\title{
PENGEMBANGAN TAHAP AWAL INDUSTRI HILIR KARET DI KABUPATEN KUANTAN SINGINGI
}

\author{
Bahruddin $^{1}$, Almasdi Syahza ${ }^{2}$, Djaimi Bakce ${ }^{3}$ Irdoni $^{1}$, Said Zul Amraini ${ }^{1}$, Ida Zahrina ${ }^{1}$, Ivan \\ Fadhillah$^{1}$, Arya Wiranata ${ }^{1}$, Syoffinal ${ }^{4}$ \\ ${ }^{1}$ Jurusan Teknik Kimia, Fakultas Teknik, Universitas Riau \\ Jl. HR. Soebrantas, Km. 12.5, Pekanbaru 28293, Indonesia \\ ${ }^{2}$ LPPM, Universitas Riau \\ Jl. HR. Soebrantas, Km. 12.5, Pekanbaru 28293, Indonesia \\ ${ }^{3}$ Jurusan Agribisnis, Fakultas Pertanian, Universitas Riau \\ Jl. HR. Soebrantas, Km. 12.5, Pekanbaru 28293, Indonesia \\ ${ }^{4}$ APKARKUSI, Desa Lubuk Terentang, Kecamatan Gunung Toar, Kabupaten Kuantan Singingi
}

bahruddin@lecturer.unri.ac.id

\begin{abstract}
Abstrak
Kabupaten Kuantan Singingi merupakan daerah produsen komoditi karet alam terbesar di Provinsi Riau. Sejumlah besar gabungan kelompok tani (GAPOKTAN) karet di beberapa desa dan didukung oleh pemerintah daerah sudah membentuk Asosiasi Petani Karet Kuantan Singingi (APKARKUSI), untuk melakukan pengendalian kualitas dan pelelangan bahan olah karet (bokar). Asosiasi ini juga berencana akan mengembangkan industri hilir berbahan baku utama bokar. Tujuan kegiatan ini adalah untuk melakukan persiapan awal terkait dengan rencana pengembangan produk hilir karet tersebut. Kegiatan tahap awal ini meliputi penentuan kualitas bokar dari petani yang berafiliasi dengan APKARKUSI, jenis produk hilir karet tahap awal dan perencanaan tata letak mesin dan sarana produksinya, dan spesifikasi yang diinginkan pasar dari produk sandal karet sebagai salah satu jenis produk hilir karet yang akan dikembangkan. Kualitas bokar yang dikelola oleh APKARKUSI relatif sangat baik (yaitu dengan kadar karet kering berkisar 60-65 \%). Jenis produk hilir karet yang siap diproduksi adalah brown crepe rubber, dimana kinerja proses produksinya masih perlu dioptimalkan. Spesifikasi produk sandal karet yang akan diproduksi bersifat dinamis, yaitu dengan mempertimbangkan faktor model, kualitas, kenyamanan dan harga. Untuk proses produksinya, perlu merujuk kepada tata letak mesin dan sarana produksi yang dapat menhasilkan kinerja yang efektif dan efisien.
\end{abstract}

Kata Kunci : bahan olah karet, crepe rubber, produk hilir karet, sandal karet, tata letak mesin produksi

\section{PENDAHULUAN}

Kabupaten Kuantan Singingi Provinsi Riau merupakan kabupaten dengan pendapatan masyarakat dan penunjang kegiatan perekonomiannya adalah sub sektor perkebunan. Terdapat tiga tanaman perkebunan yang menjadi andalan dalam pembangunan pertanian di Kabupaten Kuantan Singingi, yakni tanaman kelapa sawit, karet dan kakao (Saam \& Arlizon, 2012). Komoditi karet merupakan komoditi unggulan di Kabupaten Kuantan Singingi, sehingga pemerintah telah menetapkan karet sebagai komoditi utamanya disamping kelapa sawit dan kakao (Anggraini, Mahrani \& Hadi, 2020). 
Secara umum permasalahan yang dihadapi dalam pengembangan komoditi karet di Kabupaten Kuantan Singingi saat ini adalah rendahnya kualitas karet petani, rendahnya harga karet ditingkat petani, rantai pemasaran yang masih panjang, dan belum tersedianya industri hilir pengolahan karet. Untuk mengatasi berbagai permasalahan tersebut, Pemerintah melalui Dinas Pertanian khususnya Bidang Perkebunan telah berupaya merealisasikan pelaksanaan pembinaan kepada para petani dan pelaku usaha, penerapan teknologi pasca panen dan penerapan sistem pemasaran dalam bentuk lelang bersama, melalui kegiatan-kegiatan pembinaan dalam bentuk (Bappeda Kabupaten Kuantan Singingi, 2020):

- Pelatihan dan pendampingan kepada petani dan pelaku agribisnis karet

- Peningkatan kemampuan kelembagaan petani karet

- Peningkatan produksi, produktivitas dan mutu karet

- Fasilitasi penanganan pasca panen dan pemasaran hasil karet

- Peningkatan sarana dan prasarana teknologi komoditi karet

- Pengembangan pembibitan karet

- Pemeliharaan kebun entris dan kebun induk karet

- Pelaksanaan peremajaan karet rakyat

- Peningkatan kapasitas dan kesejahteraan tenaga penyuluh perkebunan

Sistem pengelolaan usaha perkebunan dengan produk akhir adalah bahan baku karet dalam bentuk bokar, belum mampu memberikan nilai tambah dan peningkatan pendapatan yang signifikan kepada petani karet. Harga karet ditingkat petani saat ini masih rendah dibandingkan dengan tingginya tingkat kebutuhan hidup, sehingga perlu diupayakan solusi nyata untuk meningkatkan pendapatan petani karet.

Salah satu upaya yang harus dilakukan pemerintah dan/atau sektor swasta adalah dengan kebijakan pengembangan industri hilir karet.
Diharapkan dengan adanya industri hilir karet ini akan memberikan nilai tambah dan peningkatan pendapatan kepada petani karet. Bagi Pemerintah Daerah, pengembangan industri hilir karet ini nantinya adalah sebagai salah satu sumber penerimaan daerah dalam bentuk Pendapatan Asli Daerah (Dinas Perkebunan dan Pertanian Kuantan Singingi, 2020).

Saat ini, sebagian petani karet di Kabupaten Kuantan Singingi sudah membentuk beberapa kelompok tani. Petani-petani tersebut tergabung dalam 36 kelompok tani dengan jumlah anggota sudah mencapai 1.266 yang tersebar di 5 kecamatan (APKARKUSI, 2020). Kelompok tani ini tergabung dalam Asosiasi Petani Karet Kuantan Singingi (APKARKUSI). Hingga saat ini APKARKUSI hanya menyalurkan karet hasil petani ke pabrik industri hulu yang memproduksi crumb rubber atau produk antara lainnya. Untuk meningkatkan nilai ekonomi karet, perlu dikembangkan industri hilir karet yang langsung di atur oleh APKARKUSI bekerja sama dengan pemerintah daerah Kabupaten Kuantan Singingi.

Dalam rangka pengembangan produk hilir karet alam, pemerintah kabupaten Kuantan Singingi beserta APKARKUSI mencanangkan pembentukan Badan Usaha Milik Pemerintah (BUMP). BUMP oleh APKARKUSI merupakan BUMP pertama di Kabupaten Kuantan Singingi. Dalam rangka pengembangan BUMP untuk produk hilir karet alam tersebut telah disusun skema pengembangan komoditi karet di Kabupaten Kuantan Singingi (Dinas Perkebunan dan Pertanian Kuantan Singingi, 2020).

Universitas Riau diharapkan dapat berperan sebagai pelaksana kajian dan pelatihan dalam skema pengembangan komoditi tersebut. Untuk tahap awal pengembangan tersebut, dilakukan beberapa kegiatan yang difokuskan pada mendorong penyiapan produksi produk hilir karet yang akan dilaksanakan oleh APKARKUSI. Diharapkan kegiatan tersebut dapat mendorong tercapainya rencana pengembangan komoditi hilir karet di Kabupaten Kuantan Singingi.

$$
\text { Teknologi Tepat Guna }
$$




\section{METODE}

Metode kegiatan pengabdian masyarakat ini dilakukan dalam beberapa tahapan, yaitu observasi langsung, pengambilan sampel bokar dan survey pasar. Observasi langsung dilakukan terkait dengan APKARKUSI dan kegiatannya, juga ke GAPOKTAN dan petani karet yang terafiliasi dengannya. Observasi juga dilakukan terkait dengan kesiapan APKARKUSI untuk melakukan produksi karet hilir. Hasil observasi tersebut digunakan untuk merencanakan tata letak mesin dan sarana produksi karet hilir nantinya. Pengambilan sampel bokar dimaksudkan untuk menentukan kadar karet kering (KKK) dari bokar yang sudah dikelola oleh petani karet yang berafiliasi dengan APKARKUSI. Survey pemetaan pasar dilakukan hanya untuk produk hilir karet yang akan diproduksi dalam waktu dekat, yaitu sandal karet. Fokus pemetaan pasarnya adalah untuk menentukan spesifikasi produk sandal tersebut. Pemetaan pasar dilakukan dengan observasi lapangan, penyebaran kuesioner, wawancara langsung, FGD maupun data sekunder lainnya yang tersedia.

Data yang digunakan pada kajian ini adalah data sekunder dan data primer. Data sekunder dikumpulkan dari berbagai sumber, yakni dari Badan Pusat Statistik (BPS), dinas yang membidangi perkebunan baik tingkat Kabupaten Kuantas Singigi maupun pada tingkat Provinsi Riau, Balai Besar Industri Agro Republik Indonesia, Pusat Penelitian Karet Republik Indonesia, searching internet, dan sumber-sumber lainnya.

Data primer dikumpulkan melalui pengamatan di lapangan dan diskusi kelompok terfokus (Focus Group Discussion) dengan berbagai kalangan di Kabupaten Kuantan Singingi. Diskusi dilakukan dengan melibatkan berbagai pihak pemangku kepentingan, antara lain: Dinas Pertanian Kabupaten Kuantan Singingi, Bappeda Kabupaten Kuantan Singingi, Asosiasi Petani Karet Kabupaten Kuantan Singigi (APKARKUSI), pengurus kelompok tani (GAPOKTAN), para pengusaha karet, dan pihak-pihak terkait lainnya.

\section{HASIL DAN PEMBAHASAN}

Kegiatan pengabdian tahap awal yang telah dilakukan ini menyasar terutama kepada pengelola dari APKARKUSI, yang berada di Desa Lubuk Terentang Kecamatan Gunung Toar Kabupaten Kuantan Singingi. Waktu pelaksanaannya adalah bulan Juli-September. Hasil kegiatan yang sudah dilakukan diuraian sebagaimana berikut ini.

\section{Kualitas Bokar}

Hasil analisa kadar karet kering (KKK) ratarata bokar yang dihasilkan petani karet yang tergabung dalam APKARKUSI dapat dilihat pada Tabel 1. Tabulasi tersebut disusun berdasarkan desa asal bokar di Kabupaten Kuantan Singingi. Terlihat bahwa KKK bokar yang dikelola oleh petani karet yang berada di bawah pengawasan APKARKUSI sangat baik, yaitu lebih dari $60 \%$. Umumnya KKK bokar yang dihasilkan oleh petani karet di Indonesia sekitar 55\%.

Tabel 1. Hasil Analisa Kadar Karet Kering (DRC) Bokar Petani APKARKUSI

\begin{tabular}{|l|c|}
\hline \multicolumn{1}{|c|}{ Desa } & DRC (\%) \\
\hline Pasar Baru & 61 \\
\hline Sako & 60 \\
\hline Taratak Air Hitam & 65 \\
\hline Desa Kopah & 64 \\
\hline Lubuk Terantang & 60 \\
\hline Gunung Toar & 64 \\
\hline
\end{tabular}

Sebagaimana diketahui bahwa salah satu faktor penentu kualitas bokar adalah KKK atau dry rubber content (DRC). Kadar karet kering adalah kandungan padatan karet per satuan berat yang dihitung dalam satuan persen (\%). KKK lateks atau bekuan sangat penting untuk diketahui karena, selain dapat digunakan sebagai pedoman penentuan harga juga merupakan standar dalam pemberian bahan kimia untuk pengolahan ribbed smoke sheet (RSS), karet teknis dan lateks pekat (Sari \& Fatkhurahman, 2015). Kadar karet kering pada lateks tergantung dari beberapa faktor antara lain jenis klon, umur pohon, waktu penyadapan,

Teknologi Tepat Guna 125


musim, suhu udara serta ketinggian tanaman dari permukaan laut. Terdapat beberapa metode dalam penentuan KKK, salah satu diantaranya adalah metode laboratorium (Rachmawan \& Wijaya, 2018).

\section{Tata Letak Mesin dan Sarana Produksi}

Pembuatan produk hilir karet membutuhkan beberapa alat proses, sekurang-kurangnya terdiri dari creeper, open mill, hot press, mold dan sarana pendukung lainnya. Saat ini, APKARKUSI baru memiliki satu unit alat creeper yang kondisinya belum bisa beroperasi secara optimal, seperti ditunjukkan pada Gambar 1. Mesin creeper berfungsi untuk membersihkan bokar sehingga kadar karet keringnya bisa mencapai lebih dari $95 \%$.

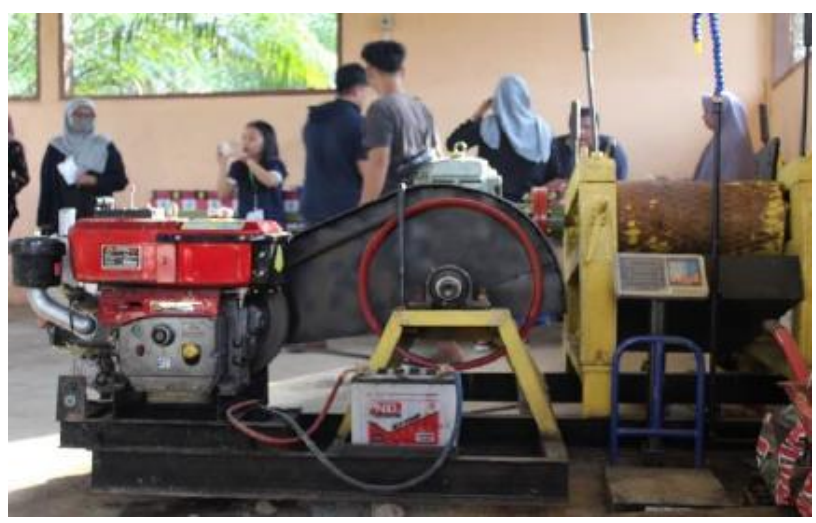

Gambar 1. Mesin Creeper

Saat ini, APKARKUSI sedang dalam tahap penyediaan alat proses dan sarana pendukung lainnya. Kajian awal dari kegiatan pengabdian ini merekomendasikan tata letak mesin dan fasilitas untuk produksi tersebut adalah sebagaimana ditunjukkan pada Gambar 2. Penataan ruang ruang tersebut diperlukan agar dalam kegiatan produksi karet hilir nantinya dapat dilaksanakan dengan efisien. Jika penataan ruang sembarang, maka dikhawatirkan akan menimbulkan ketidaknyamanan dan mengganggu proses produksi.

\section{Potensi Pasar Produk Sandal Karet}

Potensi produk sandal karet dipengaruhi oleh minat konsumen dan kondisi pasar, baik yang ada di Kabupaten Kuantan Singingi maupun di daerah sekitarnya. Hasil pemetaan pasar produk sandal karet tersebut dapat dilihat pada Gambar 3.

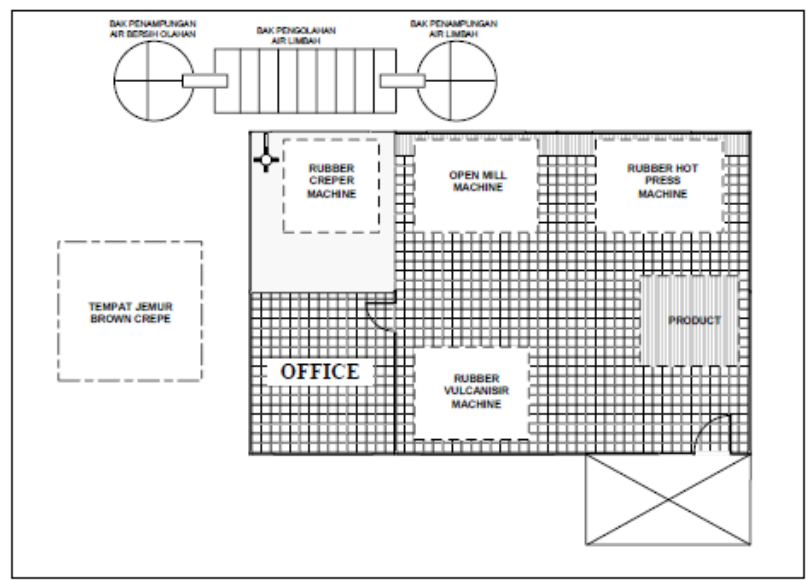

Gambar 2. Tata letak mesin dan sarana produksi produk karet hilir.

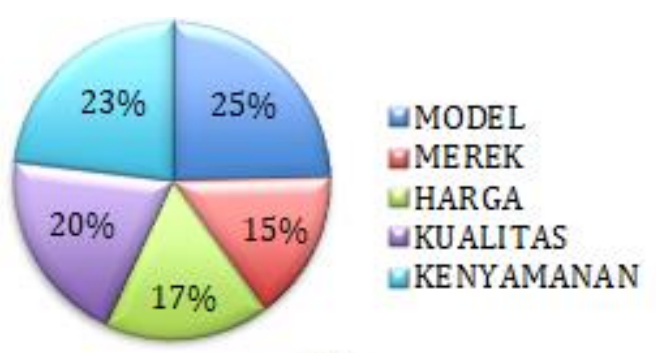

(a)

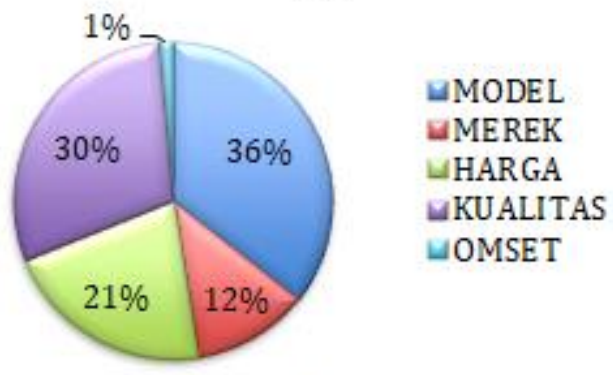

(b)

Gambar 3. (a) Faktor yang Mempengaruhi Minat Konsumen Membeli Sendal, (b) Faktor yang Mempengaruhi Daya Jual Pedagang.

Gambar 3(a) Menyajikan data persentase faktor-faktor yang mempengaruhi minat konsumen yang membeli sandal. Persentase terendah yang mempengaruhi minat konsumen terdapat pada faktor merek sandal, yaitu 15\%. Hal ini dikarenakan 
sandal merupakan alas kaki yang tergolong kebutuhan pokok, sehingga jenis ataupun merek suatu sandal tidak terlalu mempengaruhi minat konsumen. Persentase tertinggi yang mempengaruhi minat konsumen yaitu faktor model sandal. Model sandal merupakan kondisi maupun bentuk sandal yang cocok digunakan dalam kondisi tertentu. Oleh sebab itu, model sandal menjadi faktor utama yang mempengaruhi minat konsumen (Jamaluddin, \& Hydia, 2016).

Gambar 3(b) Menyajikan data presentase faktor-faktor yang mempengaruhi daya jual pedagang sandal. Data yang didapatkan bisa dilihat bahwa persentase terendah terdapat di faktor omset penjualan, dimana omset pedagang sandal tidak mempengaruhi daya jual pedagang. Hal ini dikarenakan, modal dan biaya perawatan yang dikeluarkan oleh pedagang sandal berbahan dasar karet tidak terlalu banyak dan sandal yang dijual mampu bertahan cukup lama. Adapun persentase tertinggi yang menjadi faktor daya jual pedagang sandal adalah faktor model sandal (36\%). Daya jual yang disebabkan oleh faktor model sandal selalu berbanding lurus dengan minat konsumen (Nugraha, \& Juliani, 2018).

Kegiatan-kegiatan tahap awal yang sudah dilakukan tersebut sangat berguna sebagai dasar untuk pengembangan industri hilir yang akan dilakukan oleh APKARKUSI. Penentuan kualitas bokar dapat digunakan untuk menentukan harga bahan baku bokar, neraca massa dan beban biaya proses produksi produk hilir karet. Perencanaan tata letak mesin dan sarana produksi lainnya dapat digunakan untuk kegiatan pembangunan pabrik produk hilir karet. Spesifikasi produk sandal karet, sebagai salah satu produk hilir karet yang akan dikembangkan, dapat digunakan untuk menentukan sandal karet yang sesuai dengan keinginan pasar.

Hasil kegiatan ini merupakan tahap awal dari keseluruhan tahapan pengembangan industri hilir karet di Kabupaten Kuantan Singingi. Tahap selanjutnya yang perlu segera dilakukan adalah melengkapi asesoris mesin creeper untuk mengoptimalkan kinerjanya; penyediaan sarana dan prasarana produksi, seperti mesin produksi lainnya (open mill, hot press, mould, genset dan lain-lain), gedung (gudang bahan baku/produk, proses produksi, kantor dan lain-lain) dan fasilitas air bersih dan pengolahan potensi limbah; pemetaan pasar berbagai jenis produk hilir karet yang akan dikembangkan; dan penguatan tata kelola.

\section{KESIMPULAN}

Kualitas bokar yang dikelola oleh APKARKUSI relatif sangat baik (yaitu dengan kadar karet kering berkisar 60-65 \%). Jenis produk hilir karet yang siap diproduksi adalah brown crepe rubber, dimana kinerja proses produksinya masih perlu dioptimalkan. Spesifikasi produk sandal karet yang akan diproduksi bersifat dinamis, yaitu dengan mempertimbangkan faktor model, kualitas, kenyamanan dan harga. Untuk proses produksinya, perlu merujuk kepada tata letak mesin dan sarana produksi yang dapat menhasilkan kinerja yang efektif dan efisien.

Rekomendasi tindak lanjut dari kegiatan ini adalah perlu segera dilengkapi asesoris mesin creeper untuk mengoptimalkan kinerjanya; penyediaan sarana dan prasarana produksi, meliputi mesin produksi lainnya (open mill, hot press, mould, genset dan lain-lain), sarana gedung (gudang bahan baku/ produk, proses produksi, kantor dan lain-lain) dan fasilitas air bersih dan pengolahan limbah; pemetaan pasar berbagai jenis produk hilir karet yang akan dikembangkan; dan penguatan tata kelola.

\section{UCAPAN TERIMAKASIH (Bila ada)}

Ucapan terimakasih disampaikan kepada LPPM Universitas Riau yang telah mendanai pelaksanaan kegiatan ini. Terima kasih juga disampaikan kepada pengelola APKARKUSI dan mahasiswa kukerta terintegrasi Universitas Riau tahun 2020 yang telah berkontribusi pada pelaksanaan kegiatan ini.

\section{REFERENSI}

Anggraini, D., Mahrani, M., \& Hadi, N. (2020). Analisis Pendapatan Usahatani Padi Sawah Di Desa Pulau Sipan Kecamatan Inuman Kabupaten Kuantan Singingi. Green Swarnadwipa. Urnal Pengembangan Ilmu Pertanian, 2(1): 212-214.

Asosiasi Petani Karet Kuantan Singingi (2020), Lokasi Pergudangan GAPOKTAN dan Pelelangan Bokar APKARKUSI, Survey 2020.
Teknologi Tepat Guna 
Bappeda Kuantan Singingi (2019), Kajian Pengembangan Industri Hilir Karet di Kabupaten Kuantan Singingi.

Dinas Perkebunan dan Pertanian Kuantan Singingi (2020), Lokasi Kantor Pemerintah Daerah Kabupaten Kuantan Singingi.

Jamaluddin, P., \& Hydia, M. (2016). PENERAPAN METODE CONJOIN ANALYSIS DALAM. Jurnal Sains \& Teknologi Fakultas Teknik, 4(2): 19-27.

Nugraha, H. S., \& Juliani, R. A. (2018). Pembuatan Sistem Informasi Akuntansi Penjualan dan Pembelian pada Toko Sepatu Sendal Stars Subang. Jurnal Teknologi Informasi Dan Komunikasi, 5(1): 320547.
Rachmawan, A., \& Wijaya, A. (2018). Pengaruh Kadar Karet Kering Latekspada Susut Bobot Slab Dan Lump. Warta Perkaretan, 37(1): 51-60.

Saam, Z., \& Arlizon, R. (2012). Kearifan Lokal Dalam Budaya Pekandangan Di Kabupaten Kuantan Singingi. Jurnal Ilmu Lingkungan, 5(1): 10-20.

Sari, I. R. J., \& Fatkhurahman, J. A. (2015). Review of Determining Dry Rubber Content on Processing Rubber Sheet. Prosiding Seminar Nasional Kulit, Karet Dan Plastik, 4(1): 169-180. 